\title{
A METHOD FOR THE DETERMINATION OF AIR IN PLASTIC CLAY.
}

By H. SPURRIER.

Although almost universally used in the pottery industry in the preparation of plastic clay bodies, the potters pug-mill is not an efficient piece of apparatus. Though a certain amount of pugging is necessary, an over-liberal treatment may injure an otherwise good body by the introduction of an excessive amount of air. In experimenting with pug-mills it was found desirable to determine the actual air content of various samples of clay. In making this determination it was evident that a method which actually separated and measured the contained air would be the most likely to give satisfaction. With this in view, some experiments were made in order to determine the feasibility of disintegrating samples of pugged clay in boiling water. So encouraging were the results that it was determined to extend the preliminary work so as to include the measurement of the contained air in extruded samples, thrown samples, and also in sections cut from clay filter press leaves. These simple experiments afforded some quite unexpected information in regard to the structure of the blanks examined.

The manner in which a piece of clay slakes down in water indicates at once the method of its formation. In an extruded blank, made on a special machine, we observed that the separation of the clay particles took place along longitudinal lines-indicating that the air cavities lie along parallel planes (Fig. I, $a$ ). Thrown blanks exhibited very plainly the spiral striae formed in the process of throwing (Fig. $1, b$ ). A section cut from a filter-press leaf did not slake or disintegrate in boiling water but remained indefinitely in the water without slaking down (Fig. I, c). This latter case shows clearly that it is the disruptive effect of the gas vesicles, expanding under increasing temperature, that causes the clay to slake down, thus allowing the gases to escape. 


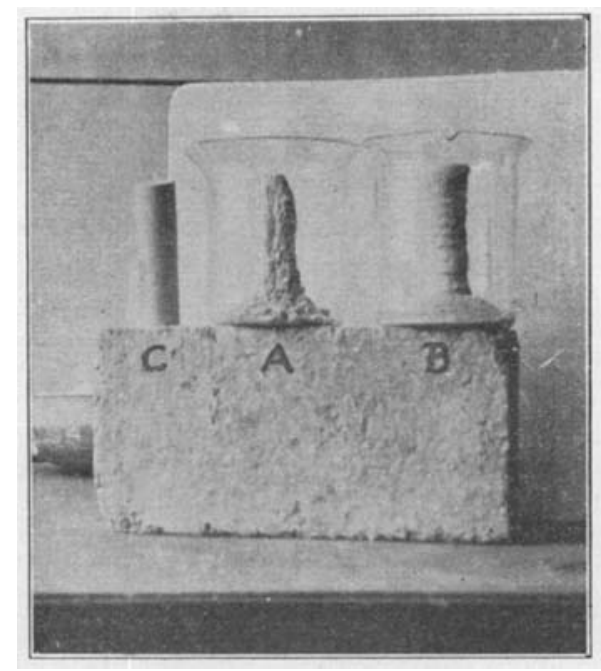

FIG. I. - Showing the behavior of clay blanks in slaking down in water.

It became evident that if the air separation could be made quantitatively it might be made the basis of a clean-cut determination. Accordingly, an apparatus was assembled to accomplish this end. It was ascertained that kerosene did not have any tendency to slake the clay or in any way disturb it, neither did it dissolve the air.

A heavy 600 cc. flask (Fig. 2, a) was fitted with a two-hole rubber stopper. The larger hole, being evenly cupped at the smaller end of the stopper, was fitted with a $7 \mathrm{~mm}$. glass tube just reaching to the bottom of the cup. The smaller hole was fitted with a right-angle bend, one limb extending to the bottom of the flask, the other terminating at a conveniently short distance from the bend; this tube was susceptible of connection with either a kerosene reservoir or a supply of boiling water (Fig. 2, $b$ ). The larger tube was surmounted by a two-hole rubber stopper entering the enlargement of the measuring tube; the other hole of the stopper was fitted with a glass tube that effected connection with and reached to the bottom of a $2500^{\circ} \mathrm{cc}$. bottle (Fig. 2, c) containing 


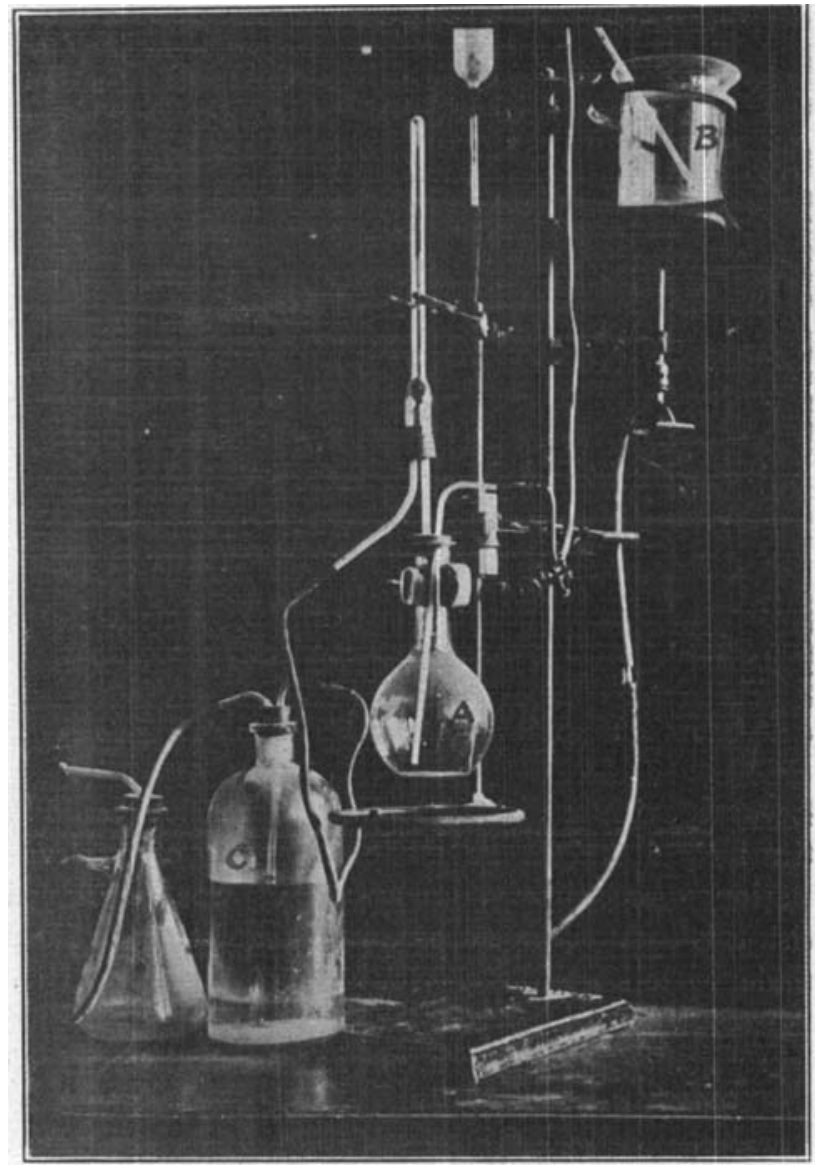

Fig. 2.-Apparatus used in the determination of the air content in clays.

500 cc. of kerosene and connected with a jet-vacuum pump. The whole was mounted on a universal stand as clearly shown. The determination is made as follows:

The duly measured (weighed if desired) blank is placed in the flask filled with kerosene which is then tightly corked. Kerosene is allowed to flow from the elevated reservoir until it overflows 
into the $2500 \mathrm{cc}$. suction bottle. The whole is then turned through an angle of about 100 degrees and more kerosene run in so as to fill the measuring tube and completely expel every bubble of air. The apparatus is then placed in erect position and clamped and the kerosene tube connected with the boiling water in the elevated liter beaker in such a manner that no air enters the tube. This manipulation requires no more dexterity than is called for in an ordinary gas analysis. The boiling water is now run into the flask, completely displacing the kerosene-the excess water running out of the system into the suction bottle - and the screwcock closed. The disintegration of the clay commences at once with the consequent liberation of the contained gases, which rise to the top of the measuring tube-duly calibrated in o.I cc. divisions for a space of $25 \mathrm{cc}$. and reading from above downward. A water bath is supported around the flask (Fig. 2, a) which is occasionally tapped with the finger tips to effect necessary agitation. The vacuum pump is set in operation causing considerable dilatation of the gas bubbles and duly facilitating their collection in the measuring tube. After about fifteen minutes, the vacuum is broken and upon equalizing the pressure by using the vacuum bottle as a leveling bottle, as customarily practiced in gas analysis, the volume of air is read and the temperature taken. The data is now in hand for calculating the volume of gas to normal temperature and pressure or any other basis preferred. The following results illustrate the application of the method:

A sample of air-free filter press clay was passed through a pugmill and the air content determined to be 9.61 per cent by volume of the clay sample--calculated at room temperature, no correction for the barometer being necessary. On passing this clay through another pug having well-set blades the air content was found to be 9.88 per cent by volume.

Another sample was passed five times through a special pug after which the air content was found to be 13.18 per cent by volume.

The method lends itself admirably to the determination of the proper blade setting of pug-mills and the determination of the soundness of pugged clay insofar as air content is concerned.

JEFFERY DEWITT Co.,

DETroIT, MICH. 


\section{DISCUSSION.}

Prof. BINNS: I have recently had occasion to take up again the question of using the French rolling table instead of the pugmill in the preparation of potters clay. There is no question in my mind but that the French rolling table is the ideal machine for preparing clay and its use would overcome a great many of the difficulties arising from the air in the plastic body. It does not, however, prepare the clay as rapidly as the pug-mill and this has been one of the objections to its use.

Mr. GorTon: I would like to ask if a determination of the air content was made upon clay which had been wedged by hand?

Mr. SPURRIER: No, we do not use the wedging process in our plant at present. At one time we used the wedging process in the preparation of the clay for a special purpose. In this case we noticed that the lamination planes in the blanks were parallel to the axis of throwing and that the distribution of the air was very uneven. It has been our experience that wedging is not a satisfactory process for the preparation of the clay blanks.

Mr. Barringer: This question of occluded air is, I think, particularly important in Mr. Spurrier's line, which I understand is the manufacture of spark plugs, where the elimination of the air is necessary to the production of the maximum mechanical and dielectric strength. It is not clear to me, however, why it is equally important to eliminate the air from other ceramic wares. I can sympathize with manufacturers of white ware, etc., who claim that the French rolling table process is too slow. Why is not the pug-mill satisfactory for the preparation of the clay for such wares? Would it not be possible to operate a pugmill under low air pressure and thus gain the desired capacity together with the complete or almost complete elimination of the air?

Mr. Lovejoy: There is one device on the market and a patent pending on another which is designed to do that which Mr. Barringer suggests; that is, to shred the clay to release the air and remove the latter by suction. The inventor who is working on this device claims that laminations and the faulty dry- 
ing which results from laminations are largely due to the included air.

Mr. SPURRIER: In regard to the removal of the air by the employment of a vacuum, I do not believe it possible to get very good results. When a piece of clay is subjected to a decreased pressure, which we improperly call a vacuum, the air vesicles expand, it is true, but they are not removed. The air vesicle may be dilated but still remains in the clay. It is very interesting to note that if a piece of clay is placed in a bottle in kerosene and subjected to alternating increased and reduced pressure, it will behave like a piece of rubber. The air vesicle is not removed but increases and decreases in size with the variations in pressure.

Mr. BRown: Would it be possible to remove the air from a clay slip in that way?

Mr. SPURRIER: Yes, that is being done. If you subject a slip in a bottle to reduced pressure, it will increase in volume, and if you tap the bottle with the knuckles, a leaden sound is given forth, indicating a lack of continuity. If the evacuation has continued long enough and all of the air is removed, the bottle will ring when tapped. The removal of the air from a heavy slip by evacuation is not practicable.

Mr. BARRINGER: The statement confirms my opinion that air may be worked from a clay by some such method as kneading but is not readily removed by reducing the outside air pressure. As to pugging under reduced air pressure, I believe that this would involve considerable mechanical difficulty in the operation and maintenance of the apparatus. 